\title{
Between Knowledges: Pacific Studies and Academic Disciplines
}

Edvard Hviding

\section{Opening Up? Reclaiming a Plurality of Knowledges}

\begin{abstract}
A
rapidly and unpredictably transforming world requires transformed research approaches, as reflected in calls for interdisciplinarity-a concept easily invoked but a research approach less easily implemented. Regionally oriented research of wide thematic scope such as Pacific Islands studies-whose past we want in the present context to honor, and to whose future we would like to contribute-aspires toward understanding a wonderful diversity of human lifeworlds that can hardly be interpreted within a single-discipline framework. A multitude of perspectives is needed in this research. I argue, however, that interdisciplinary practice is about more than a methodological combination of existing academic disciplines, and that a successful interdisciplinary approach should cause the epistemological, methodological, and institutional boundaries between disciplines to be disturbed, even remade. I here think about such disturbance of academic disciplines and hegemonies specifically in the context of broadly conceived, regionally comparative social and cultural research (with integration of environmental dimensions) as exemplified by Pacific studies. ${ }^{1}$

Approaching the diversity of Pacific worlds from an appreciation of human creativity requires an interdisciplinary inclusiveness that extends beyond academic disciplines in the humanities, social sciences, and natural sciences into local worldviews and indigenous epistemologies, taking these on board as partners in dialogue and collaboration toward a plurality of knowledges. In the following I discuss interdisciplinarity in Pacific studies specifically in the context of this challenge of developing mutually inspiring communication among knowledges sometimes deemed distant, but in
\end{abstract}

The Contemporary Pacific, Volume 15, Number I, Spring 2003, 43-73

(C) 2003 by University of Hawai'i Press 
fact sharing fundamental concerns about understanding the world. This would involve institutional and ideological reorientation of the dichotomy between, in Vince Diaz' words, "who theorizes and who is theorized" (Diaz, personal communication, quoted in White and Tengan 200I, 385). In a more general perspective I have a parallel agenda in this paper: to give a critical view of the idea of interdisciplinarity in terms of its uneasy political role in contemporary debates in and beyond academia about how research should be organized (whether for epistemological, political, or bureaucratic reasons).

Under the agenda announced for the Center for Pacific Islands Studies 2000 conference, calls for "interdisciplinarity" in Pacific studies are hardly to be separated from calls for "decolonization" of Pacific studies. As pointed out by Mere Roberts in the interesting preconference discussion posted on the center's website from September 2000 onward, a "silent but pervasive colonization of intellectual spaces ... has had the effect of marginalizing indigenous knowledge systems." 2 Not that the taking-on-board of the indigenous epistemologies of Pacific peoples is solely up to initiatives of the academic establishment: As noted recently in the pages of this journal, "Villagers are ... themselves exploring how they construct knowledge: instead of always being the subject of research by outsiders, which they often see as exploitation, they are undertaking the recording and writing of their own cultures based on their indigenous epistemologies. Indigenous epistemology refers to a cultural group's ways of theorizing knowledge" (Gegeo and Watson-Gegeo 200I, 55). Views from the "inside" of the dynamic, self-labeled field of Native Pacific Cultural Studies have also noted (with reference to the work of Linda Tuhiwai Smith [1999] on indigenous peoples and the decolonizing of research methodologies) how "a growing number of us Pacific scholars ... approach research from a communitarian perspective, that is, research that is not only applied (targeted to making positive changes) but is firmly anchored in Indigenous or Native epistemologies and methodologies" (Gegeo 200I, 492, italics, parentheses, and capitals as in original). Such processes, then, set out a path not just toward decolonization, but also toward a further stage of dehegemonization, in the words of Gegeo and Watson-Gegeo (200I). They also encourage interdisciplinary approaches, collaborations, and projects of the "inclusive" kind proposed above. When so much is happening among Oceania's villagers and indigenous scholars, all of whom in various ways show little reverence for the boundaries of conventional academic disci- 
plines, the wider scholarly and institutional totality of Pacific studies surely has potential for creating a distinct form of interdisciplinarity where boundaries are dissolved, not only between disciplines, but also between the categories of insider, outsider, subject, object, scholar, and native. ${ }^{3}$

Considering now the relationship between transformed realities of local and global worlds and revised research approaches for those worlds, our time is often presented as one in which standard solutions to problems are eroded and increasingly unsatisfactory. The nation-state no longer appears to provide standard solutions to problems experienced by its citizens (see discussion such as that in Hobsbawm 2000). Long-established disciplines no longer appear to provide adequate solutions to pressing research problems that can be harbored in no single specific academic field. Disciplinary boundaries are contested and discarded and new forms of scholarship emerge. From a certain fashionable angle, "globalization" and its corollary, "increased complexity" (adding the often-invoked metaphor of "hybridity") are considered the driving forces behind much of this: Current research problems in social and cultural studies (including postcolonial studies and those addressing the decline of the nation-state) emerge from the appreciation of people's increasingly complex and tangled lifeworlds. This is not to say that globalization and complexity are unproblematic concepts in relation to aspects of the current state of world affairs as experienced by local people. To the contrary, it may be argued that the notion of increased complexity is one of the most questionable metaphors currently in vogue in social and cultural studies of globalization. Local cultures, the metaphor suggests, are simple - especially those apparently small-scale societies that only now, at this late stage in world history, are seen to be "emerging," as it were, into the complex world of the global (according to misguided but long-lived notions of non-European "peoples without history" [Wolf I982]).

"Hybridity," another prominent concept in globalization studies, could be viewed as equally questionable given its semantic connotations of preexisting pure entities (cultures?) that have somehow been combined in a higher "hybrid" condition; purities mixed and muddled, as it were, by entanglement of heterogeneous sources. It has been argued that the fashionable use of this master metaphor in cultural studies to identify "hybrid cultures" - as if the human world ever did consist of well-delimited cultures whose boundaries only recently became blurred-says more about those who use it to classify, than about that and those classified (Friedman 
I997, 269). The concept's extended use to denote "hybrid disciplines"approaches combining elements from many different sources-is of particular interest in a discussion of interdisciplinarity in Pacific studies, since the notion of hybridity appears to be of importance in Native Pacific Cultural Studies, recently the focus of an important symposium held in the Pacific Rim location of the University of California, Santa Cruz, a stronghold of the postcolonialist/postmodernist orientation in cultural studies. ${ }^{4}$ To quote Teresia Teaiwa's subsequently published contribution to that symposium (a highly innovative split text that weaves parallel recent histories of Pacific studies from a "native" point of view): "The native is hybrid. Hybridity is essential. For the Edge" (Teaiwa 2001, 344, italics in original).

\section{Complexity and Connectedness in the SEA OF IsLANDS}

Metaphors of complexity, hybridity, and flux seem to have considerable currency as far as Oceania is concerned. Anthropological, archaeological, historical, and linguistic research in the region, as well as the voices of Pacific Islanders themselves, have told the world in no uncertain terms that social life in Pacific societies was never "small-scale," nor "simple." We need only invoke the well-known example of the large Pacific world according to Polynesian navigator-priest Tupaia, whose horizons as presented to Captain Cook in 1769 included "every major group in Polynesia except Hawaii and New Zealand, ... [extending] for 2,600 [nautical] miles from the Marquesas in the east to Rotuma and Fiji in the west, equivalent to the span of the Atlantic" (Lewis 1972, I7n). Nor has ever-evolving cultural flux throughout the region been a problem or a threat to local distinctiveness; Oceania presents many a contradiction to the common assumption that cultural difference is generated by spatial distance and isolation (and to its corollary, that spatial proximity promotes blending).

In villages around the Marovo Lagoon in Solomon Islands, where I have been working as an anthropologist for a long time, I have met with many thinkers who present and discuss their own theories of ecology, prehistory, and linguistics in contexts of migration, isolation, and dispersal. I have listened to long accounts of how certain bird species not previously present, such as the large, conspicuous hornbill and a small brown tern, arrived in the area at the time of ancestor so-and-so and since then have established themselves in certain ways and become useful for people in 
other ways. Likewise, the people of Marovo (located in the New Georgia islands of the western Solomons, an area of possible significance for furthering knowledge of early Austronesian migration further into the Pacific) readily hypothesize how skin color and other physical characteristics indicate that their own ancestors probably came from the northwest, whereas the slightly different characteristics of a neighboring group indicate physical ancestral influence from another direction. Similar discussions concern the long-term dispersion of different languages in the New Georgia archipelago, including the replacement of a couple of languages now no longer remembered, and how totally unrelated languages are able to coexist among peoples who are otherwise "just the same" in terms of their kastom. Although these islanders build their discussions and interpretations on oral histories, traditions of regional networks, and histories of social relationships-rather than using concepts from western science such as species colonization, phenotype and genotype, genetics, or diffusion-the concerns, interests, and issues are analogous and express a fundamental preoccupation not with isolation, but with interisland, intercultural contact and influence.

Attention to the long-term and present dynamics of regional connections among Oceania's islands, including local histories of networks, promises globally comparative lessons for addressing urgent problems in world development. Significantly, patterns of cultural diversity and processes of intercultural exchange and migrations in Oceania are themselves constitutive of social life and political relations (see Friedman and Hviding 200I). There is not, nor has there been, much isolation among the far-flung islands and archipelagos of Oceania. And for Pacific Islanders, lives have always to some degree been culturally complex, with everyday connections far beyond the home island. Thus it is not the case that the worldor the Pacific, or Oceania-has suddenly become complex, requiring new and more complex research agendas to be devised and pursued by those who wish to understand the world or any of its regions. In his influential and by now universally quoted article, "Our Sea of Islands," Epeli Hau"ofa (I993) argued that western social scientists—as well as the politically empowered elites of the Pacific and of aid donor nations and organizations-had misunderstood the Pacific by consistently envisioning this greatest of oceans in terms of "islands in a far sea": isolated points with separate but comparable human existences wretchedly dependent on the exporters of development aid and trade goods and the importers of labor 
migrants. Arguing instead that rather than a collection of far-flung islands in the sea, the larger regional whole of Oceania is a "Sea of Islands," Hau"ofa invoked a notion that "home" is not necessarily confined to a specific location, but may well include the entire Oceanic space within which peoples are able to, and do, move. This part of Hau'ofa's argument resonates with long-term migration patterns in regional cultural history (the settlement of the entire tropical and subtropical Pacific by the Lapita peoples over the last 4,000 years [Kirch I997]), as well as present-day lifeworlds.

\section{Diversity and Difference in Pacific Studies AND BEYOND}

Oceania is indeed a region of much diversity and many intriguing matters, cultural and natural. For Pacific Islanders (whether they are connected across sea, as in Hau'ofa's model, or across land, as in the larger islands of Melanesia [see Jolly 200I for a critical examination]), life has in a fundamental sense always been complex, with different people, thoughts, and material things perennially on the move, and it is fair to say that single disciplines have always been insufficient for understanding the connected lifeworlds of the peoples of Oceania. This being recognized, there has for a long time been much traffic across disciplinary boundaries in research on this region, and much transformation in what are viewed as established elements of specific disciplines. From its overall ambition of a holistic approach to human lives and such much-maligned essentialist concepts as cultures and societies, my own field of Pacific anthropology has often expanded its scope into other disciplines. Universities of the region also have a relatively long history of institutionalized relationships between disciplines, under such labels as Pacific history (and prehistory, although that term in itself has unfortunate connotations) and-indeed-Pacific [Islands] studies. This long record of already existing collaboration between disciplines, and its associated focus on interdisciplinary approaches to (at the very least) multidisciplinary research problems-as exemplified recently by a dazzling synthesis of longer lines in Pacific history by Patrick V Kirch (2000)-are not to be taken for granted in the academic world, and may indeed be unique in creating connections between disciplinary approaches whose boundaries are often abandoned en route. For Pacific studies, this is certainly one aspect from the past to be honored while creating the future. ${ }^{5}$

Interdisciplinarity is not new, then, either as label or as practice, for 
those who work in Pacific studies. Neither is the notion of cultural complexity; but the way in which some pressing global concerns have been manifesting themselves recently in the Pacific may point to some distinctive local responses to the present-day forces of globalization that defy earlier, simpler models of reality. In part, these responses are distinctive because they draw on already existing patterns of response established in earlier phases of globalization. Oceania has been globalized before by such diverse forces as colonialism, trade, missions, and aid. Indeed, as pointed out by historian Eric Hobsbawm (2000, 6I), the "globalization" unfolding in today's world is a historical process long in the making-yet it has gained considerable speed and intensity over the last ten years or so. In line with this there is reason to argue that certain recent events in Oceania, such as those connected to the activities of Asian logging companies in Melanesia (see Barlow and Winduo 1997 for comprehensive reviews), are in fact more complex - and certainly less predictable - than the rather locked development scenarios implied by portrayals of small Pacific nations under the MIRAB acronym (Migration, Remittances, Aid, Bureaucracy; see Bertram and Watters I985; Poirine I998).

In a recent book, geographer Tim Bayliss-Smith and I have attempted to analyze the staggering repertoire of developments occurring in the western Solomon Islands during the I990s, when a range of transnational logging companies, mostly of Asian origin, and a similar range of conservationist nongovernmental organizations (NGOs) of Australian, New Zealand, North American (and even ostensibly global) origin, competed for the goodwill of the villagers of New Georgia who own the rainforest and the trees, and who often wanted to pursue their own projects, in line with neither the capitalist logic of logging companies nor with the global moralities promoted by nongovernmental organizations (Hviding and BaylissSmith 2000; see also Hviding 1998). To follow these competing narratives and contradicting strategies (as well as for the sake of historical and ecological contextualization), we found it necessary to work jointly from our own two disciplines and also to draw on concepts, models, and materials from disciplines and domains of knowledge such as history, archaeology, linguistics, ecology, botany, soil science, and-most notably-indigenous knowledge of the rainforest. This raises an important point about multiand interdisciplinarity today: Many emerging research problems are not simple stories; they straddle a number and range of conventional disciplines, and so researchers would do well to follow suit without concern for academic boundaries. If research on contemporary issues in the contem- 
porary Pacific requires any form of discipline-based approach to expand into other, possibly unrelated disciplines (such as when the anthropologist has to read up on the volcanic soils of the Solomons and the international economics of the timber trade), then that is probably one of the paths outlined for the future of Pacific studies. But whereas I cannot propose to foresee where Pacific studies is heading, and how it will proceed, I am convinced that the calls for interdisciplinarity emerging from many corners-including those who would advocate it as a "hyperpoliticized" (Diaz and Kauanui 200I, 323) path toward decolonization and dehegemonization-do not nearly address the full range of challenges for the future of Pacific studies. Notably, it is a difficult task to challenge and transform the institutional structures of academic disciplines that appear to make "interdisciplinarity" locked to notions of dialogues between disciplines, not knowledges in a wider sense.

Let me give an example from other shores. Where I come from in Europe the intensifying calls for interdisciplinarity emanate not least from a bureaucracy intent on undermining scholarly freedom and subjecting academia to cost accounting. It has often struck me that the unflinching messages from government ministries and university administrators in Norway, Scandinavia, and Western Europe about the need for interdisciplinary research somehow seem to echo the unstinting beliefs held by the alchemists of Europe's Middle Ages: Things and substances of great value (eg, gold) can be magically obtained by mixing and transmuting lesser things and substances. So too for the modern-day administrator who believes that research of the greatest value can be obtained through mixing existing disciplines by locating their respective practitioners under one roof (in an interdisciplinary research center) or under one budget (in an interdisciplinary research program). I would counter such efforts of dubious alchemy by noting that interdisciplinary studies emerge more fruitfully in actual, voluntary, and dialogical encounters between representatives and practitioners of different disciplines/sciences/knowledges in pursuit of solutions to major concerns that straddle many a boundary-a process during which the boundaries themselves are threatened and new forms of collaboration emerge in the spaces between.

\section{Knowledges in the Plural}

The spaces between conventional disciplines-the moveable, unpredictable "inter" dimension of interdisciplinarity, in contrast to the side-by-side 
ordering of multidisciplinarity-are a crucial contemporary and future focus. ${ }^{6}$ But let us also expand this notion of communication among disciplines into a pluralized view of multiple knowledges (Worsley 1997); thus confounding the positivist search by conventional western science for "exact knowledge" in the hegemonic singular. In an important and richly detailed book studying knowledge systems as far apart as Oceanic navigation, Central-African medicine, and North American consumer culture, Peter Worsley (1997) started out with the puzzle of why anthropologists have tended to refer to local knowledges about things and processes in the human environment as "ethnoscience." Why characterize other people's sciences with the prefix "ethno-"? he asked rhetorically (recognizing how he himself had been doing so for most of his career). Let me play devil's advocate and propose some implications of Worsley's observation. When prefixed with "ethno-," a specific field of local knowledge (such as "Fijian ethnobotany") becomes entangled in an unequal relationship with western science, in which the latter is deemed canonical and a standard for evaluating the reliability and other attributes of local knowledge. Indeed, in most cases "ethno-" is affixed to names of disciplines that western epistemology considers to be "objective science," based on the rigors of hypothetical-deductive method (Hviding I996b; compare Popper I980).

Checking a dictionary of anthropological terms (Seymour-Smith I986), we discover an astonishing variety of what a research administrator in Solomon Islands, in a conversation with me, once referred to in the plural as "ethno-somethings" (he had just received several research applications proposing to pursue several different "ethno-[sciences?]" in various locations of the Solomons). We find ethnomedicine, ethnobiology, ethnobotany-rather well-known concepts-but also ethnomathematics, ethnoastronomy, and many other ethno-versions of western sciences. One notable exception here is that of conventional anthropological practice, in which the four "pillars" of any society, the so-called "privileged systems" (Schneider 1984), are referred to without "ethno-" prefixes: kinship, religion, economy, and politics. There is, of course, "ethnohistory," but that term was in vogue chiefly when history was considered a more objective domain of knowledge; its use faded as the past came to be seen to be constructed, even "invented" (see, eg, Hobsbawm and Ranger I983). With changing political climates, tribal peoples' own histories were also treated as history proper (see Wolf I982). In a parallel vein it should be noted that academic and political attention has risen, expanded, and rallied around the obvious fact that Oceania's peoples not only have their own histories but also 
their own sciences: a few years ago the huge diversity of knowledges held by Pacific Islanders themselves was the subject of a large conference at the University of the South Pacific called "Science of Pacific Islands Peoples" (Morrison, Geraghty, and Crowl 1994a; I994b; 1994c; 1994d). Significantly and happily, the editorial preface to the four volumes of conference proceedings is free of any "ethno-" prefixes, instead noting that the proceedings contain "a unique collection of traditional scientific and technical knowledge from the Pacific Islands," thus addressing an urgent need to "give due attention to Pacific knowledge of plants and animals, astronomy, medicine, agriculture, navigation, boat-building, fishing, and other fields of knowledge as well to the conceptual and linguistic ways of organizing this knowledge" (Morrison, Geraghty, and Crowl I994, vii). We might of course discuss why the editors chose to label these sciences of Pacific Islands peoples "traditional" - but let me give them the benefit of doubt and observe that it should be possible to view "sciences" on a nonfixed "traditional-modern" continuum without implying hierarchy and epistemological incommensurability.

In a properly inclusive multidisciplinary perspective, the entire "ethnosomething" catalogue, lifted out of its hierarchical context, is a potential treasure trove for the global expansion of knowledge horizons. This potential has been obscured by the positivist search in "ethnoscience" for underlying cognitive structures and for correspondence or discrepancy between nonwestern classifications and western Linnaean taxonomy (Hviding I996b). From the point of view of natural sciences, for example, it has been far too easy to write off local knowledge based on the notion that it is somehow inherently incompatible with western science. More recent work on Pacific Islanders' knowledge of fishes and other inhabitants of the marine environment has demonstrated many instances of an empirical orientation toward natural phenomena, amounting to local versions of hypothetical-deductive method (eg, Hviding I996a; 1996b; Johannes 198I). A comparative study of epistemologies may illuminate some striking connections between sciences previously deemed to be far apart.

I next elaborate on this argument for wide interdisciplinarity-connecting conventional academic disciplines and indigenous (in this case Pacific) knowledges-by examining some foundations of epistemology, and their practical consequences, in the Marovo Lagoon area of Solomon Islands. ${ }^{7}$ At this stage it is perhaps necessary to note that I work from the assumption that the anthropological study of human lifeworlds, from a globally 
comparative view of the human condition, is a legitimate activity in its own right. As a European anthropologist based in western academia I do not bow to allegations that all such work in nonwestern places is exploitative. In my work among and with the people of Marovo Lagoon I have had the privilege of being encouraged and allowed (by the Marovo people) to pursue projects directly engaging Marovo worldview, epistemology, and language with, for example, western sciences and the meanings of the English language, some of the results of which have been two multilingual and-I would hazard - transepistemological books on environmental knowledge and oral traditions (Hviding 1995a; 1995b). ${ }^{8}$ The following attempt at illuminating some creative engagement of Marovo knowledge with other knowledges builds directly on the circumstances of fieldwork, the aims and agendas of which were in part determined not by the anthropologist but by his hosts.

\section{EPISTEMOLOGICAL ENCOUNTERS: Spaces Between KNOWledges}

A processual, hypothesizing epistemology prevails in Marovo on a foundation of successive states of acquisition and validation of knowledge (inatei). From initially hearing about (avosoa) something, one enters a state of knowing (atei). Accumulated knowing and further transmission of knowledge in social situations determine whether or not the higher level of believing (va tutuana, lit., imbue with truth) is reached. Through repeated verifying instances of seeing for oneself (omia), believing is transformed into the level of trusting (norua, lit., be convinced of efficacy) and into the personal state of being wise (tetei). An immediate realm of human presence in a potentially dangerous environment, generalizable to many corners of Oceania, may serve as an illustration. For six days of the week an average of at least 200-300 men of the villages of Marovo spend much of the daylight time diving on the deep outer reefs facing the ocean, spearfishing and collecting commercial shells. This presence of people in seas populated by fairly large numbers of potentially dangerous sharks very rarely leads to any form of attack by sharks on humans. It is argued in Marovo that the only people who have ever been killed by sharks there were from kin groups (butubutu; see Hviding I996a) that do not have a totemic relationship to these sole man-eaters in the Marovo environment (with the exception of the dreaded saltwater crocodile, to which certain butubutu 
have a similar relationship). For a number of historical reasons, shark totemism (entailing a prohibition against mentioning by name, provoking, harming, killing, and most of all, eating sharks) is only associated with and practiced by a limited number of the localized butubutu of the Marovo area, namely those with a maritime-oriented history and ancestral territorial holdings of mainly reefs and sea. The observation that sharks tend to attack people from land-oriented groups who lack a special relationship with them-in fact a common postulate in coastal areas of Solomon Islands-is regarded by Marovo fishermen as a validation of the belief that ancestrally imposed respect shown to the shark will in return give protection from attacks in the present. Remembered instances of fatal attacks are considered to be the test or trial (chinangava) of the ancestrally derived belief in the efficacy of shark totemism, and from believing (va tutuana) in the idea one becomes convinced and elevates it to the level of trusting (norua).

To address issues located firmly in the "spaces between knowledges," I move to a field of Marovo practice that involves epistemological challenges of western science from a basic local notion of comparability. The seasonal capture of nesting marine turtles is based on a complex body of knowledge about life cycles, nesting habits, and hatching periods of two species of marine turtles. The major guardian of this field of maritime knowledge and practice was the late David Livingstone Kavusu (I926I999). During fieldwork in I986 I had the privilege of being invited by Kavusu to join him and some of his sons on the annual pre-Christmas turtle-hunting expeditions. His condition was that I allowed him to make me knowledgeable (va atei) before departing for the outer islands on which turtles nest. During a week's basic education about turtles, Kavusu expressed some of his epistemological foundations to me:

all this about turtles came from Tetepare [a large and now uninhabited island south of Marovo], because those people there were people of the ocean. My father ... wanted me to know [atei] all about turtles so that I would keep that knowledge. I did believe [va tutuana] what he told me. But I could not trust it [norua] until I had seen [omia] it all by myself. So I went out there, and I found some turtle nests, and I dug up the eggs and counted them, and I examined those eggs well to mark the time when those turtles would return. Then I went back to the mainland, but when it was time for the first of the turtles to return I was back on that island. And they came up, first one, and then the others that I had marked. Then I knew that it worked, what my father had told me. And I could trust it. 
The details of examining nests and eggs and thereby accurately predicting the time and place of a turtle's return to nest again cannot be described here. However, during each November-February season the people of four small villages on one of the weather coasts of Marovo "mark" and capture as many turtles as they require for the end-of-year cycle of Christmas, New Year, and wedding celebrations. There appears to be a near total correlation between mark and capture. People also point out that, since the small islands where turtles nest are a full day's paddling from the villages, it would not be worthwhile to go out there at all if they could not trust their own predictions. From a skeptical point of view one might argue that so many turtles come up to nest anyway, what is regarded as one "marked" turtle could in fact be any one. But these beaches are not of the type where thousands of turtles nest, and the overall numbers of turtles and human visitors during any season are far too small for chance encounters to be frequent.

The axiomatic point about turtle eggs is that according to received Marovo wisdom they take exactly 2 I days to hatch. Since turtles always come ashore to lay their eggs at night, the eggs hatch on the twenty-first subsequent night—any hatchlings emerging late, in daytime, are devoured by seabirds and other predators. Having been educated by Kavusu to the level of knowing this, I was puzzled some months later to find that a number of technical reports and authoritative reviews stated that the hatching time of eggs from these species of turtle was from 55 to 70 days (eg, Vaughan I98I; Carr I984). In mid-I987 I told Kavusu about these assessments based on research in a range of tropical locations (including parts of the Solomons), and asked him what were his thoughts about the grave discrepancy. His immediate reaction was, "That is either a lie, or they are different turtles!" I assured him that the species were the same, by referring to identifications given in reports on marine turtles in Solomon Islands (eg, McElroy and Alexander 1979). This produced the following inspired response, in direct translation and only slightly abridged:

I do not know how those people have found this out. But as I see it, it is a great lie! Me, I would probably be able to tell you a lie or two on things like fish or in stories about kastom, because some of that I do not know very well. But turtles! What I know about turtles is right there in my heart, turtles are inside my life, and what I tell you about turtles is true-and I know it is true. . . The old men told me that juvenile turtles come out of the eggs after twenty-one days, and I did believe in what they said, but that was not enough for me. I had to go and see it with my eyes, for myself. 
So I went out to the islands, and I found a new nest, and I checked the eggs to find out when the turtle would come back, but I didn't dig them all up-I left them there. So I tied the knots [referring to tying a number of knots on a bark string corresponding to the number of nights left until the predicted return of the turtle; one knot is then removed after each night]. And I stayed there on that little island, and one Sunday came, and two Sundays came, and that turtle came up again to lay new eggs after fourteen days, just how I had marked and tied the knots, following what my father had taught me. And I checked the eggs of the first nest of that turtle, and they hadn't hatched yet, but there were tiny turtles inside. So I waited, and on the seventh night after the return nesting, on the twenty-first night after that first nest was made, baby turtles came out. They made a hole in the sand and then they came out one by one, and a long line of them ran down across the sand into the sea. I have seen this, and I know that when I tell you twenty-one days, it is true. Not once, but twice have I stayed for days and days out there to study this. So I tell you: After seven days, when the suko [a calcified spot spreading out over the shell of a new egg] covers the whole egg, that egg is all white. And from this day, blood is inside that egg. Seven days more and we come to fourteen days. The mother turtle will come up again, if she is a vonu pede [hawksbill turtle; green turtles are known to have slightly different cycles], and now you can see a small turtle inside the eggs of the first nest if you break one. It is a real turtle with head, eyes, legs. It is a turtle, but it is not ready to come out yet. Seven more knots, and that night is the time for that small turtle to come out and run to the sea. One or two days before that, the shell of the egg has started to break. And on this twenty-first night, it has to be at night, the new turtles dig their way up and they run to the sea, everyone from one nest together. This is how I know it is. ...

I don't think those scientists have really gone to the islands and lived there for a long time to count all their fifty or sixty days. They have used their minds to find this out. They haven't seen it, I think. Maybe, one of them went to one island and found a nest and put a mark on that nest. But he didn't watch over that nest day and night, all the time. No, he had to go back to his office, and then when he came back to check on the nest he had marked, some other turtles had disturbed the mark. You know how big turtles make a mess out of the beach when they come up. So they made a mess out of his mark; it was stuck in the sand by another nest. And then he didn't see those first eggs, that the baby turtles in them came out on the twenty-first night. Somehow, he thought when he returned after fifty days and the nest with the mark was empty, that the eggs took so many days to break open. But he got it all wrong. This is how I think it happened. But as for me, the islands and turtles belong to me, and I know what I say is true, because I have seen it myself! It is finished now. 
The empirical, deductive approach taken by David Livingstone Kavusu in his argument for the validity (and indeed superiority) of his own knowledge is striking. I can only admit that I find Kavusu's case for a hatching period of 2I days at least as convincing as the presentation of the 55-70 days' hatching period documented in scientific reports. The extraordinary discrepancy nevertheless creates a major puzzle. Kavusu's reflections extend into comparative epistemology. When the knowledge he trusts is challenged by information from the field of western science, he ponders over what mental processes and methodological constraints may have produced the (in his view) erroneous notion held by western turtle biologists. $\mathrm{He}$ also suggests practical circumstances of research that may have led to misinterpretation.

Identifying the epistemology of Marovo, as represented by a recognized expert thinker like Kavusu, as fundamentally of an empirical orientation does not imply any necessary correspondence with a canonical paradigm of western science. Indeed, Kavusu's exposition of this body of practical knowledge could be seen as representing its own scientific paradigm. Indigenous and western scientific theories (the latter in this case including "natural laws" identified by biology) may be seen as alternative paradigms with potentials for convergence, competition, and conflict. It is not my aim to argue for or against privileging any one paradigm for understanding what marine turtles do in the western Solomon Islands. Rather, my point is that one cannot reach an understanding of what people do in relation to turtles, and to other parts of the environment, solely by relying on a comparison of indigenous knowledge with western science, giving epistemological privilege to the latter. Let me note that the discussion between Kavusu's unwritten, indigenous knowledge and the biological knowledge written by the scientists in their reports took place only indirectly, as I communicated the latter to Kavusu. It would have been very interesting to develop direct communication about this particular contentious issue from a view of including indigenous epistemology in research and education more generally (see Meyer 200 I for an important analysis of Hawaiian epistemology in the context of educational reform), but structures of remoteness (in many senses) prevented this.

Truly interdisciplinary approaches to understanding how people live and think must incorporate acute sensitivity to the need for decolonization also in the sense exemplified here-through the pluralization of knowledges, a subsequent search for possibly unexpected connections between 
them, and a refusal to take epistemological barriers for granted. It is indeed so, as conveyed to us from Roland Barthes through Vilsoni Hereniko in the preconference discussion on the Internet, that engaging in interdisciplinary studies should be about the "creation of a new object, which belongs to no one." That object emerges in the spaces between knowledges, in encounters between practitioners who may be more or less surprised that they share some basic concerns and premises. However, the ambition to create something new, belonging to no one, appears to be inevitably and forever connected to knowledges already held by someone.

History shows us many interesting examples of connections between knowledges, sometimes occurring unexpectedly. I mentioned earlier Polynesian navigator Tupaia and British navigator Cook, who no doubt experienced moments of epistemological convergence at least in the sense of knowing and appreciating the interests and concerns of the other regarding the geography of the South Pacific. Another, less well-known example from the days when Europeans sailed around the Pacific in search of their own discoveries may elaborate the argument and round off this part of the discussion. In his comparative analysis of the epistemologies of scientific practice and discovery, Bruno Latour (1987, chapter 6) recounts what happened on I 7 July I787, when the French explorer Lapérouse arrived in his ship L'Astrolabe at a largely unknown area of land in the far north Pacific, called "Segalien" or "Sakhalin" in older sources. The explorer's immediate question was whether this was an island or a peninsula-not least because "a fierce dispute had ensued among European geographers" (Latour 1987, 215) as to the accuracy of old maps and records that variously showed Sakhalin as an island or as a peninsular outcrop of Asia. Scientific disputes about unknown parts of the world proliferated in Europe in those days and led to the financing and dispatch of many expeditions.

As soon as the shore party landed, a few "savages" came to the beach and exchanged salmon for pieces of iron, and Lapérouse was astonished but pleased when it turned out that "not only did [the 'savages'] seem to be sure that Sakhalin was an island, but they also appeared to understand the navigators' interest in this question and what it was to draw a map of the land viewed from above" (Latour 1987, 216). Lapérouse and his expedition never returned to France, as his two ships were wrecked in I788 on the reefs of Vanikoro in the eastern Solomon Islands, with no known survivors. But in his notes about the Sakhalin "map-drawing" incident in his account of the expedition, based on journals sent home at 
intervals, Lapérouse remarked on how "the ease with which they had guessed our intentions led me to believe that the art of writing was not unknown to them" (Valentin 1969, 78). A moment of discovery in the more extended sense, and a moment of epistemological convergence between knowledges?

\section{INTERdisCIPLINARITY: A VieW From AfAR}

Having now proposed an optimistic view of the potential for inclusiveness in wider dialogues between knowledges-Pacific and western, practical and scientific-I wish to change tack sharply and discuss some more general, rather programmatic positions about interdisciplinarity in the Pacific and beyond. My perspective is that of comparative contrast: Encouraged by the conference organizers (I was asked to report on how interdisciplinarity is handled and interpreted in my part of the world), I present a "view from afar." Since I990 I have been involved in discussions about this elusive concept and its implications through my work as an advisor to the national Research Council of Norway. It is in fact no coincidence that interdisciplinarity should be a major concern for research policy in Norway. Since the emergence of the report of the World Commission on Environment and Development (WCED I987), headed by Norway's then Prime Minister Gro Harlem Brundtland, our relatively small nation has expressed and implemented a commitment to the aims of development as set out in the Brundtland commission's report. The commission's legacy, the concept of sustainable development, must have reached every corner of the world - perhaps because, like interdisciplinarity, it sounds good, but remains an elusive expression of compromise. Indeed, it has been argued that "sustainable development" has become very popular among politicians and development bureaucrats precisely because, to quote Bill Adams, it "implies radical reforms without at all specifying what ought to be changed and without demanding any specific measures at all" (I990).

From the late I980s huge political and bureaucratic support for sustainable world development in post-Brundtland-report Norway led to a major reorganization of research funding and policy. With new grants from the government our four universities quickly established interdisciplinary, interfaculty centers for studies of environment and development. The politically expressed drive toward interdisciplinarity was a main focus of this period. Research funds were channeled into programs founded on 
the rather acceptable notion that interfaces between environment and development must be addressed from the interfaces of many disciplines, especially in terms of new links between the natural and social sciences. In I993 the Research Council of Norway was dissolved and regrouped under several new divisions, each of which was to be interdisciplinary in scope and nature. The Division for Environment and Development took on responsibility for research on everything from polar glaciology (as long it was deemed to have something to do with the environment) to popular culture (as long as it was deemed to relate to "developing countries" and thus had something to do with development).

Among the impressions and lessons learned about interdisciplinarity from this Norwegian context (where it was established overnight, metaphorically speaking) is the realization that research at the environmentdevelopment interface has to take into account human subjective lifeworlds and natural objective facts simultaneously-if not in one and the same researcher, then at least in dedicated centers and research groups. I do not propose an immediate connection between the tight, heavily bureaucratized, and nationally circumscribed world of Norwegian research policy and the rather boundless and widely dispersed realm of Pacific studies. Nevertheless my observations on interdisciplinary approaches may hold some promise for addressing the issue-if not the context-from where we stand in our search for holistic and inclusive understandings of events in Oceania. At the very least, any discussion of "development" and transformation in Pacific Islands societies (ranging from indigenous concepts to the global morality interventions of nongovernmental organizations [Gegeo I998; Hviding 1998]) must have an interdisciplinary scope, both to allow for the unexpected and-paraphrasing an important comment by Caroline Sinavaiana-Gabbard, again from the conference's on-line discussion board-to acknowledge that an interdisciplinary view most closely approximates the worldviews of Pacific peoples. We ought to take interdisciplinary approaches to studying the human lifeworlds of Oceania because those lifeworlds are in themselves "interdisciplinary," as it were. I should like to add that the worldviews of virtually any people must by definition transcend the relatively single-minded, compartmentalized concerns of academic disciplines.

The Brundtland commission emphasized the totality and complexity of global problems concerning environment and development, and noted that these problems "cannot be treated separately by fragmented institu- 
tions and policies" (WCED I987, 37). This emphasis on totality and complexity-in 1987-was carried along into a great range of national, international, and global research policy conferences addressing sustainable development and the need for studies integrating natural and social dimensions. A typical post-Brundtland conference statement said: "Special care and diligence should be exercised in developing innovative research themes and strategies especially with a view to promoting cross-sector, multidisciplinary and interdisciplinary research" (NAVF I988, II). But despite such strongly stated ambitions, these post-Brundtland documents reflect (with very few exceptions) a diffuse, unclarified attitude to interdisciplinarity. Challenges of a wider methodological and deeper epistemological nature were barely addressed. In 1992, An Agenda of Science for Environment and Development into the 2 Ist Century was published (Dooge and others 1992). This ambitious document specifically stated the need for integration of the natural and social sciences to address the issues at hand (Dooge and others 1992, I0; italics in original). In these debates it has been easy to concur on the importance of interdisciplinarity; however, it turns out to be far more difficult to discuss its contents, let alone to develop and implement interdisciplinarity as a principle in research practice. Instead, interdisciplinarity easily appears as a free-floating general and relatively unsubstantial "attribute" of any research policy in Norway (and similar places) geared to following the influential recommendations of the Brundtland commission and subsequent documents.

To sum up the post-Brundtland Norwegian perspective on research for sustainable development (applicable anywhere in the world, for that matter): Viewed broadly and inclusively, research on the interfaces between environment and development addresses processes of social and environmental change, to understand cultural, social, economic, ecological, technological, or political transformations-and to contribute to a knowledge base for reaching the aims of sustainable development. From this it follows that we are looking at research focused on the specific challenges to knowledge production that are generated at the interface between the well-being of the natural environment and the ongoing transformations of societies and economies, the well-being of people. Such definitions clearly direct us toward types of research problems that are in their very nature interdisciplinary, and that pose challenges requiring the contribution of a potentially large number of disciplines in the natural and social sciences and the humanities. Collaboration along such lines demands flexibility 
from involved researchers, and a will and ability to learn about the ways of other disciplines without necessarily embarking on interdisciplinary work in a stricter sense. Thus, interdisciplinarity is about far more than simply adopting certain approaches and tools used by other disciplines; it involves research problems to which no single discipline has an answer. An open question remains, subject to much debate, whether or not students first require a solid grounding in one specific discipline before they can engage in pluralist explorations across a range of other knowledges and methodologies. Any such broad aspirations to straddle many fields are further complicated by today's increasing fragmentation of disciplines through internal specialization and the emergence of "hyphenated" disciplines.

\section{Maneuvers in-Between: Politics of InTerdisciplinarity}

Of necessity, ambitions of interdisciplinary collaboration raise general epistemological questions about differences and similarities among disciplines in methodologies and conceptual repertoires. Considerable disparities exist in the ideologies of sciences-disagreements that bear on how disciplines, and the production of knowledges in general, are practiced, controlled, and utilized. Established single disciplines each have a considerable repertoire of research methods and concepts in everyday use and under constant further elaboration. The greater the theoretical consolidation within a discipline - that is, the more it is dominated by a single paradigm - the more agreement exists on methodology and overall aims. Referring to Thomas Kuhn's classic treatise on paradigms (I962), it may be argued that the social sciences differ from the natural sciences by being multiparadigmatic. But considerable difference also exists within the social sciences broadly conceived: It is clear that economics, for example, is much more dominated by a single paradigm than is sociology or anthropology. In the latter disciplines internal divisions may be as solid as boundaries drawn between them and neighboring disciplines. Particular conflict has been present in the social sciences (and some of the humanities) between the positivist camp, arguing that these disciplines must strive toward the objective ideals of natural science, and a critical antipositivist camp, arguing that the objectivity of the social sciences is qualitatively different from that of the natural sciences-and therefore, paradigmatic pluralism must follow logically.

Such lines of academic conflict also relate to what may be termed "the 
price of interdisciplinarity." It is often argued that interdisciplinary research must be evaluated according to "normal scholarly criteria." Persistent skepticism within university departments toward interdisciplinary teaching and research programs appears to be a worldwide phenomenon. Many would in this context say rhetorically that ideally, interdisciplinary research should meet the standards required by any single discipline involved. Tall orders like this make interdisciplinarity a difficult project indeed, located in the spaces between disciplines, which themselves often diverge strongly in basic ideological orientations. We risk being overly optimistic about the potential for solving multidisciplinary problems through interdisciplinary innovation. Such optimism could be seen as unconsciously arrogant, lacking in appreciation of the complexity of the matters addressed, and overestimating the possible contributions of broad (as opposed to deep) research approaches. Over optimism on behalf of broad approaches that draw their tools from many disciplines (the selfascribed interdisciplinary field of cultural studies is a particularly relevant case) may become problematic in regional contexts of cultural, social, political, and ecological variation and complexity-not least characteristic of today's Oceania. Further potential pitfalls of oversimplification lie in the political self-definition of nonwestern regional specialties (such as Pacific studies) as distinct approaches that have already achieved interdisciplinary integration in teaching and research. Such conceptual circumscription of complex problems by politicized notions of interdisciplinarity may be taken to imply that nonwestern complexities are approachable without the high degree of deep and long research specialization applied to the western world.

Other approaches to knowing the great region of Oceania may be seen as considerably more problematic in their lack of attention to researchbased knowledge, however. I am thinking about the great multitude of western nongovernmental organizations currently at work in most corners of Oceania on a special mission of conservation and sustainable development. Papua New Guinea, Solomon Islands, and Vanuatu today experience an unprecedented level of engagement and investment from European, North American, Australian, and New Zealand nongovernmental organizations-a situation probably unparalleled in the "developing" world when one considers the small populations and generally low media, political, and strategic profile held globally by these Pacific Island nations. On national levels, these activity fields unfold and evolve largely beyond 
the reach of inherently weak nation-states. In this sense NGO involvement in modern Melanesia, albeit sometimes in tandem with much more localized and long-established churches, constitutes a "sector" amounting to what in other kinds of state formations would be referred to as "civil society." In the sometimes lucrative market for consultancies in the broad field of Pacific Islands sustainable development (including such favored areas of attention as "community-based development"), broadly conceived and ostensibly multidisciplinary techniques such as "Rapid Rural Appraisal" (eg, Chambers I98I) are brought to bear on increasingly complex situations where the nongovernmental organizations themselves are protagonists, and the local people being involved in the NGO projects largely focus on the maintenance of a certain simplicity in everyday life (see Hviding and Bayliss-Smith 2000; Friedman 1997).

Although some partnerships between nongovernmental organizations and researchers have been established, notably in the context of community-based conservation in Papua New Guinea, nongovernmental organizations at work in the Pacific have not particularly been known for making use of existing knowledge often based on long-term field research. Despite much rhetoric about "community-based" matters, it also appears that such organizations' globally universalist moralities and standardized methodological toolboxes have accomplished little in the way of providing a place for Pacific Islanders' own knowledges and epistemologies. For example, the people of Marovo Lagoon, who not only know much about turtles and sharks but who also have a long and rich experience of dealings with outside worlds, seem to recognize little of themselves, their concerns, and their lifeworlds in the quantitative cost-benefit analyses offered by Greenpeace to exemplify and demonstrate small-scale economic alternatives to logging, oil palm plantations, and other industrial developments threatening the rainforests of the area (LaFranchi and Greenpeace 1999).

\section{SUMMing UP}

Interdisciplinarity is certainly an ambition strongly in line with challenges posed by the current climate of knowledge seeking-in the Pacific and elsewhere. Moreover, and perhaps more importantly, an inclusive integration of knowledges has potential for being a research approach more closely in tune with the world as experienced by the people who live in it-particularly if dialogue and interaction is achieved, and boundaries increasingly dissolved, between the understandings of insider and outsider, native and 
scholar. Elements of such integration have been developed through many decades of Pacific Islands studies and gain particular momentum today with the rapidly increasing contributions of indigenous scholars and the transformation of nonindigenous scholarship after years of de- and reconstruction. But tensions still remain to be resolved in a number of fields: between bureaucratic and scholarly ambition; between indigenous knowledges and academic disciplines with regard to hegemonic power; between deconstructive and constructive approaches to innovation in research agendas; and between Pacific studies and the Pacific Islanders whose worlds are studied. Above all, perhaps, we always need to broaden the view of research beyond that of conventional disciplines; not to dissolve the disciplines, I claim, but to loosen up the boundaries, recognizing the spaces between, and incorporating other knowledges-that is, those of indigenous Pacific Islanders-in an inclusive scheme that promotes interactions among the many different knowledges of, in, and about Oceania. On a further global note, Pacific studies might fruitfully engage with other regional studies to attain "interregionality" in perspective, particularly concerning the gloomy issues of conflict, disruption, and violence on national levels that have gained momentum in today's Oceania. Coups, civil wars, and ethnic strife have their parallels in other parts of the world - and a broadened scope for understanding recent events in the Pacific may benefit from dialogue with that wider world. New phenomena pose new challenges on new horizons and require new knowledges.

No single discipline possesses a conceptual approach capable of grasping the total interplay of processes directing change and transformation in specific societies at specific times. Deepened understanding of this interplay is therefore dependent on our ability to maneuver between disciplines - and benefit from the spaces in-between-in the context of interdisciplinary research. However, interdisciplinary understanding-across disciplines and also by necessity integrating a wider variety of knowledges, including indigenous ones-cannot be produced by teaching and research programs oriented simply toward drawing an increasing number of loose fragments from different disciplines. For Pacific Islands studies, the most important measure is not the number of knowledge fragments known and mastered and put to use; it is the gaining of insight into processes that tie such fragments of knowledge and understanding together in mutual inspiration, support, and dependence. The approaches of different knowledges, whether institutionalized as disciplines or existing in local, unwritten forms, can yield insights into different relations and processes ranging 
across the cultural, the social, the political, the ecological, and more. Interdisciplinarity implies the ability to combine different knowledges and their insights into significant projects and practices-formulating innovative, more proper research for reaching greater, more holistic understanding of how Pacific worlds have been, are, and will be constituted and remade.

THIS PAPER IS BASED on my address of the same title given at the 2000 conference of the Center for Pacific Islands Studies, University of Hawai'i. In the process of revising and expanding it for publication I have benefited from comments by Vilsoni Hereniko and Terence Wesley-Smith. My thanks to the center for inviting me to the conference, and to many conference participants for inspiring conversation and exchanges across many knowledges and boundaries. For comments and discussion on issues raised in this paper I wish to convey special thanks to the speakers and panelists in the conference session on interdisciplinary approaches (Vili Hereniko, Jon Kamakawiwo'ole Osorio, Graham Hingangaroa Smith, and Ming-Bao Yue), as well as to Bob Kiste, Epeli Hau'ofa, Teresia Teaiwa, Vince Diaz, Jojo Peter, John Moffat Fugui, Murray Chapman, and Ron Crocombe.

\section{Notes}

I I therefore refrain from a wider conceptual and methodological discussion of interdisciplinarity in strictly "scientific" terms; what I am after here is a specific focus on the twin challenges posed on the one hand by the thematic scope, ambitions for comparative analysis, and indigenous scholarly presence in Pacific studies, and on the other by the politicized celebration of interdisciplinarity as a "right way" in and (not least) beyond academia.

2 The website address is <http://www.hawaii.edu/cpis/conference/preconf disc.html >; the link to the discussion board was discontinued, however, as the website gave room for the center's $200 \mathrm{I}$ conference in New York. In this paper I highlight some of the contributions to the 2000 preconference discussion to acknowledge their integral role in the conference process, and to state my appreciation of this inspiring initiative from the conference organizers.

3 See the contributions in Diaz and Kauanui (200I; see note 4 below) for the state-of-the-art in such creatively probing interdisciplinarity of today's Pacific studies; a pioneering, by now classic, example of such scholarly work-ethnographically grounded yet transcending any number of conventional disciplinary boundaries as well as the insider/outsider dichotomy-is Vilsoni Hereniko's Woven Gods (I995). 
4 The symposium, "Native Pacific Cultural Studies on the Edge," was held II-I 2 February 2000 at Center for Cultural Studies, University of California, Santa Cruz. Contributions to the symposium by Teresia Teaiwa, Jon Kamakawiwo'ole Osorio, Geoffrey White and Ty Kawika Tengan, Margaret Jolly, James Clifford, David Welchman Gegeo, and convenors Vicente M Diaz and J Kēhaulani Kauanui, were published in a special issue of the present journal (Diaz and Kauanui 200I). According to one of the contributors, “'On the Edge' describes the place, the position I believe some of us believe we feel we must, prefer, or fear to occupy as pioneers of the new scholarship" (Teaiwa 200I, 343)-and this volume demonstrates well the breadth and intensity of Pacific scholarship on Pacific worlds, while also serving as an intense glimpse into a transformed understanding of Oceania that emerges from "border wars with native scholars on the one hand and with interdisciplinary cultural studies on the other" (White and Tengan 200I, 384).

5 Meanwhile we may also ponder something else, not to be celebrated: The lack of indigenous Pacific Islander participation in the academic disciplines and projects of Pacific anthropology and related fields (see White and Tengan 200I for extensive discussion of the "absence of Pacific Islanders in the ranks of professional anthropology").

6 I do not elaborate here on the many different discussions among researchers and others about concepts and approaches of "multidisciplinarity" and "interdisciplinarity." Briefly, multidisciplinarity implies practitioners of different disciplines working together side-by-side in addressing a defined problem-a process that does not necessitate or imply the adaptation of methods from one discipline by another and which retains a somewhat static quality, leaving the participating disciplines and the boundaries between them intact. Interdisciplinarity, on the other hand, would seem to refer most often to a more dynamic process in which proponents of different disciplines contribute collaboratively to each other's work and to a further joint project, more or less planned and predictable, of understanding across theoretical and methodological boundaries, through the fusing of knowledge, models, and approaches. In a general sense interdisciplinarity appears more often than not as a positively value-laden concept with assumed potential for achieving any number of progressive scientific, political, or other ambitions, avoiding the constraints of conventional disciplines.

7 The following discussion of Marovo epistemology builds on a more detailed analysis given in Hviding (r996b), where a deeper discussion is attempted concerning the convergence and discrepancy between knowledge systems, and concerning the philosophical implications of such epistemological interaction.

8 These two books were written on the request of the Marovo Area Council in response to concerns over knowledge loss and natural resource depletion voiced in the mid-I980s during a series of "community workshops" preceding the 
I990s wave of extraordinary NGO presence in the Solomons. Under a grant from the Research Council of Norway a combined total of I,000 copies of the books were distributed in 1996 to all schools and villages of Marovo, and to selected libraries in the Pacific region. This work has an interesting story: In the years 1985-1989 the Marovo Area Council and the Western Province of Solomon Islands implemented the "Marovo Lagoon Resource Management Project" with some support from the national government and intermittent funding from the Commonwealth Science Council and regional Pacific agencies. In addition to workshops with invited speakers and much use of established local institutions of conflict management, the project also extended invitations to some overseas scholars in a pioneering attempt to integrate locally useful research with rapid accumulation of needed knowledge about marine and terrestrial resources and their local management (see Baines and Hviding 1992, 1993; Hviding and BaylissSmith 2000, 295-297).

\section{References}

Adams, William C

1990 Green Development: Environment and Sustainability in the Third World. London: Routledge.

Baines, Graham B K, and Edvard Hviding

1992 Traditional Environmental Knowledge from the Marovo Area of the Solomon Islands. In LORE: Capturing Traditional Environmental Knowledge, edited by Martha Johnson, 92-I I $\mathrm{O}$. Ottawa: International Development Research Centre.

I993 Traditional Ecological Knowledge for Resource Management in Marovo, Solomon Islands. In Traditional Ecological Knowledge: Wisdom for Sustainable Development, edited by Nancy M Williams and Graham B K Baines, 56-65. Canberra: CRES, Australian National University.

Barlow, Kathy, and Stephen Winduo, editors

1997 Logging the Western Pacific: Perspectives from Papua New Guinea, Solomon Islands, and Vanuatu. Special issue of The Contemporary Pacific 9 (I).

Bertram, I G, and R F Watters

I985 The mirab Economy in South Pacific Microstates. Pacific Viewpoint 26:497-520.

Carr, Archie

I984 [1967] The Sea Turtle: So Excellent a Fishe. Austin: University of Texas Press. 
Chambers, Robert

I98I Rapid Rural Appraisal: Rationale and Repertoire. Public Administration and Development I (2): 95-106.

Diaz, Vicente M, and J Kēhaulani Kauanui, editors

200 I Native Pacific Cultural Studies on the Edge. Special issue of The Contemporary Pacific I3 (2).

Dooge, J C I, G T Goodman, J W M la Rivière, J Matron-Lefèvre, T O’Riordan, and F Praderie, editors

1992 An Agenda of Science for Environment and Development into the 2 Ist Century. Cambridge: Cambridge University Press.

Friedman, Jonathan

I997 Simplifying Complexity: Assimilating the Global in a Small Paradise. In Siting Culture: The Shifting Anthropological Object, edited by K F Olwig and K Hastrup, 268-29r. London: Routledge.

Friedman, Jonathan, and Edvard Hviding

$200 \mathrm{I}$ Islands Connected: Making Pacific Worlds. In Migrations and Exchange in Historical Perspective, edited by Paul Wallin, 4-9. No Barriers Seminar Papers, Vol 3. Oslo: The Kon-Tiki Museum, Institute for Pacific Archaeology and Cultural History.

Gegeo, David Welchman

I998 Indigenous Knowledge and Empowerment: Rural Development Examined from Within. The Contemporary Pacific I0:289-3I 5.

200I Cultural Rupture and Indigeneity: The Challenge of (Re)visioning "Place" in the Pacific. The Contemporary Pacific I3:49I-507.

Gegeo, David Welchman, and Karen Watson-Gegeo

200I "How We Know": Kwara'ae Rural Villagers Doing Indigenous Epistemology. The Contemporary Pacific I 3:55-88.

Hau'ofa, Epeli

I993 Our Sea of Islands. In A New Oceania: Rediscovering Our Sea of Islands, edited by Eric Waddell, Vijay Naidu, and Epeli Hau'ofa, 2-I6. Suva: University of the South Pacific. Reprinted in The Contemporary Pacific 6:I48-I6I (I994).

Hereniko, Vilsoni

I995 Woven Gods: Female Clowning and Power in Rotuma. Pacific Islands Monograph Series I 2. Honolulu: Center for Pacific Islands Studies and University of Hawai'i Press.

Hobsbawm, Eric (with Antonio Polito) 2000 The New Century. London: Little, Brown \& Co.

Hobsbawm, Eric, and Terence Ranger, editors I983 The Invention of Tradition. Cambridge: Cambridge University Press. 
Hviding, Edvard

I995a Kiladi oro vivineidi tongania tingitonga pu ko pa idere oro goana pa Marovo / Of Reef and Rainforest: A Dictionary of Environment and Resources in Marovo Lagoon. Bergen: Centre for Development Studies, University of Bergen, in cooperation with Western Province Division of Culture, Gizo, Solomon Islands.

I995b Vivinei tuari pa Ulusaghe / Custom Stories of the Marovo Area. Recorded, edited and translated by Edvard Hviding. Bergen: Centre for Development Studies, University of Bergen, in collaboration with Western Province Division of Culture, Gizo, Solomon Islands.

I996a Guardians of Marovo Lagoon: Practice, Place, and Politics in Maritime Melanesia. Pacific Islands Monograph Series I4. Honolulu: Center for Pacific Islands Studies and University of Hawai'i Press.

I996b Nature, Culture, Magic, Science: On Meta-Languages for Comparison in Cultural Ecology. In Nature and Society: Anthropological Perspectives, edited by P Descola and G Pálsson, I65-1 84. London: Routledge.

I998 Western Movements in Non-Western Worlds: Toward an Anthropology of Uncertain Encounters. Journal of the Finnish Anthropological Society $23(3): 30-5 \mathrm{I}$.

Hviding, Edvard, and Tim Bayliss-Smith

2000 Islands of Rainforest: Agroforestry, Logging and Ecotourism in Solomon Islands. Aldershot, UK: Ashgate.

Johannes, R E

I98I Words of the Lagoon: Fishing and Marine Lore in the Palau District of Micronesia. Berkeley: University of California Press.

Jolly, Margaret

200I On the Edge? Deserts, Oceans, Islands. The Contemporary Pacific I 3:4I 7-466.

Kirch, Patrick Vinton

I997 The Lapita Peoples: Ancestors of the Oceanic World. Oxford: Blackwell.

2000 On the Road of the Winds: An Archaeological History of the Pacific Islands before European Contact. Berkeley: University of California Press.

Kuhn, Thomas S

I962 The Structure of Scientific Revolutions. Chicago: University of Chicago Press.

LaFranchi, Christopher, and Greenpeace Pacific

1999 Islands Adrift? Comparing Industrial and Small-Scale Economic Options for Marovo Lagoon Region of the Solomon Islands. Suva: Greenpeace Pacific. 
Latour, Bruno

I987 Science in Action. Cambridge, m A: Harvard University Press.

Lewis, David H

I972 We, The Navigators: The Ancient Art of Landfinding in the Pacific. Canberra: Australian National University Press.

McElroy, J K, and D Alexander

I979 Marine Turtles of the Solomon Islands Region. SPC-MFMs / Turtles / WP I I. Noumea: South Pacific Commission.

Meyer, Manulani Aluli

200I Our Own Liberation: Reflections on Hawaiian Epistemology. The Contemporary Pacific I3:I 24-I 48 .

Morrison, John, Paul Geraghty, and Linda Crowl

I994 Preface to the Series. In Science of Pacific Island Peoples, Volumes I-IV, edited by John Morrison, Paul Geraghty, and Linda Crowl, vii-viii. Suva: Institute of Pacific Studies, University of the South Pacific.

Morrison, John, Paul Geraghty and Linda Crowl, editors

I994a Science of Pacific Island Peoples, Volume I: Ocean and Coastal Studies. Suva: Institute of Pacific Studies, University of the South Pacific.

1994b Science of Pacific Island Peoples, Volume II: Land Use and Agriculture. Suva: Institute of Pacific Studies, University of the South Pacific.

I994c Science of Pacific Island Peoples, Volume III: Fauna, Flora, Food and Medicine. Suva: Institute of Pacific Studies, University of the South Pacific.

I994d Science of Pacific Island Peoples, Volume IV: Education, Language, Patterns and Policy. Suva: Institute of Pacific Studies, University of the South Pacific.

NAVF (Norwegian Research Council for Science and the Humanities)

I988 One Earth-One World. Report from a research policy conference on environment and development, Oslo, 22-23 March I988. Oslo: NAvF.

Poirine, Bernard

I998 Should We Hate or Love Mirab? The Contemporary Pacific Io:65-I05.

Popper, Karl R

I980 [1959] The Logic of Scientific Discovery. Ioth impression, revised. London: Unwin Hyman.

Schneider, David M

I984 A Critique of the Study of Kinship. Ann Arbor: University of Michigan Press.

Seymour-Smith, Charlotte

I986 Macmillan Dictionary of Anthropology. London: Macmillan. 
Smith, Linda Tuhiwai

I999 Decolonizing Methodologies: Research and Indigenous Peoples. London: Zed Press.

Teaiwa, Teresia $\mathrm{K}$

200I Lo(o)sing the Edge. The Contemporary Pacific I3:343-357.

Valentin, F

I969 [1 839] Voyages and Adventures of La Pérouse. Translated from the French by Julius S Gassner. Honolulu: University of Hawai'i Press.

Vaughan, P W

I98I Marine Turtles: A Review of Their Status and Management in the Solomon Islands. Honiara: Ministry of Natural Resources.

wCED, World Commission on Environment and Development I987 Our Common Future. Oxford: Oxford University Press.

White, Geoffrey, and Ty Kawika Tengan

200I Disappearing Worlds: Anthropology and Cultural Studies in Hawai'i and the Pacific. The Contemporary Pacific I3:38I-4I6.

Wolf, Eric R

I982 Europe and the Peoples Without History. Berkeley: University of California Press.

Worsley, Peter

I997 Knowledges: What Different Peoples Make of the World. London: Profile Books.

\section{Abstract}

In this paper, I critically examine a number of notions about interdisciplinary research approaches to the challenges posed by the world today. I juxtapose this critique with a discussion of interdisciplinary developments in Pacific studies, raising questions as to how deeper dialogues between academic disciplines and the worldviews of Pacific Islanders may be reached. While interdisciplinarity is widely seen as a politically correct agenda for contemporary research on processes of globalization and development, caution is needed against prevailing optimism about the potential for solving multidisciplinary problems through interdisciplinary innovation. Such optimism may overrate the potentials of broad (as opposed to deep) research approaches and may reflect disregard, if not arrogance, toward the complexity of the matters addressed. The drive in some European countries for research on "sustainable development" indicates close ties between interdisciplinary aspirations and the bureaucratic ambitions of research administrators. Under such circumstances interdisciplinarity becomes an object of institutional 
conflict and internal debate between institutions, as well as between bureaucrats and scientists, more than a question of creative epistemological contact between plural knowledges in and beyond academic disciplines in a search for increased knowledge more generally. The avoidance of such pitfalls in the further development of Pacific studies requires close attention to and appreciation of initiatives from within Oceania, coming from beyond the domains of conventional disciplines. In this paper, such paths toward interdisciplinarity are exemplified in a discussion of epistemological encounters between Oceanic and western knowledges, and with reference to the emerging currents of "Native Pacific Cultural Studies."

KEYWORDS: anthropology, globalization, indigenous epistemologies, interdisciplinarity, Pacific studies, research policy 